\title{
Altered PCA3 and TMPRSS2-ERG expression in histologically benign regions of cancerous prostates: a systematic, quantitative mRNA analysis in five prostates
}

\author{
Riina-Minna Väänänen ${ }^{1 *}$, Natalia Tong Ochoa ${ }^{1}$, Peter J. Boström², Pekka Taimen ${ }^{3}$ and Kim Pettersson ${ }^{1}$
}

\begin{abstract}
Background: PCA3 and TMPRSS2-ERG are commonly overexpressed biomarkers in prostate cancer, but reports have emerged demonstrating altered expression also in areas outside the tumour foci in cancerous prostates. Our aim was to measure PCA3 and TMPRSS2-ERG expression systematically in all regions of prostate cross-sections, matching the data to corresponding tissue morphology.

Methods: TMPRSS2-ERG and PCA3 mRNA levels were measured with quantitative reverse-transcription PCR assays in 270 samples from cross-sections of five radical prostatectomy specimens. ERG expression was examined by immunohistochemistry.

Results: TMPRSS2-ERG mRNAs were detected in three patients and in 15 tissue samples in total. These included two carcinoma samples and 13 histologically benign samples, eight of which were located next to malignant tumours or PIN (prostatic intraepithelial neoplasia) lesions and five of which did not reside in the vicinity of any evident carcinoma foci. ERG protein expression was limited to areas of TMPRSS2-ERG mRNA expression, but did not identify all of them. PCA3 expression was detected in all five cross-sections, with statistically significant, three-fold higher expression in carcinoma regions.

Conclusions: TMPRSS2-ERG expression was detected in carcinoma foci, regions next to them, and in samples not adjacent to carcinoma foci. Claimed as a cancer-associated phenomenon, this fusion gene measurement could, if validated with a larger cohort, be utilized as an addition to histological analysis to predict current or future cancer risk in men with negative biopsies. Molecular changes outside the carcinoma foci are also indicated for PCA3, as its expression was only moderately increased in the carcinoma regions.
\end{abstract}

Keywords: Prostate, Cancer, Biomarker, RNA, Reverse transcriptase polymerase chain reaction

\section{Background}

The proposed idea of field cancerization - phenomenon first described by Slaughter and colleagues in 1953 [1] comprises the assumption that in cancers, originally a larger area of the tissue than merely the tumour focus can be changed due to inherent mutations or environmental factors. The hypothesis has been supported by several studies reporting molecular level alterations not only in the carcinoma tissue of an organ containing a malignant tumour, but

\footnotetext{
* Correspondence: riinaminna.vaananen@gmail.com

'Department of Biotechnology, University of Turku, Turku, Finland Full list of author information is available at the end of the article
}

also in the area outside the cancerous region [2, 3]. Both aberrant protein expression and mRNA transcript levels have been described [4]. Besides providing an interesting perspective to understanding carcinogenesis, detectable consequences of the field effect phenomenon could be used to supplement diagnostics.

Prostate cancer is a disease with a growing incidence and a heterogeneous nature, and the heterogeneity of the disease has made diagnostics and prognostics challenging. The currently used biomarker, PSA (prostate specific antigen) measured from blood, cannot reliably confirm the presence of cancer in the prostate since increased levels 
are frequently found also in other prostatic diseases such as hyperplasia and prostatitis. Present routine to establish the prostate cancer diagnosis is based on the histological examination of core needle biopsies that are taken with trans-rectal ultrasound guidance. However, the biopsy cores represent a random sampling of the overall tumour load regarding the aiming of the biopsy needle to the estimated carcinoma location. A histologically benign biopsy result leads to a negative cancer diagnosis, but based on the previous reports on molecular level alterations in cancer-adjacent tissues, it may be premature in determining the status of the patient.

Alterations in the expression of prostate cancer marker candidate genes TMPRSS2-ERG (transmembrane protease, serine 2; ETV-related gene) and PCA3 (prostate cancer antigen 3 ) have previously been detected by us and others [5-9]. The changes were specifically seen in the histologically benign areas of cancerous prostates but not in similar areas of prostates that were free of clinical cancer. This study was designed to systematically locate the regions of differential expression of these genes in single cross-sections of five cancerous prostates and evaluate whether the location of the carcinoma was associated with TMPRSS2-ERG or PCA3 mRNA levels or ERG protein expression.

\section{Methods}

\section{Sample collection}

To measure the mRNA expression of the target genes by quantitative reverse-transcription PCR (qRT-PCR) in prostate tissue, prostate cross-sections covering the entire organ were obtained fresh from five prostates (hereafter referred to as prostates A, B, C, D, and E) from men undergoing robotic assisted laparoscopic radical prostatectomies due to prostate cancer at Turku University Hospital, Turku, Finland in June-September 2013. Five consecutive patients with previous diagnosis of prostatic adenocarcinoma in transrectal biopsies were enrolled in the study. Patients with diagnosed adenocarcinoma in both lobes and patients with clinical suspicion of multifocal or large tumour were excluded from the study. The sample collection protocol is depicted in Fig. 1. Briefly, a horizontal tissue slice of $2 \mathrm{~mm}$ in thickness was removed from each prostate and further cut into $5 \times 5 \times 2 \mathrm{~mm}$ pieces systematically with sterile blades, avoiding cross-contamination between pieces. A Styrofoam plate with a $5 \times 5 \mathrm{~mm}$ grid was used to record the two-dimensional location of each piece, resulting in a unique coordinate code for each piece of tissue. Depending on the size of the organ, this procedure yielded 48 individual samples for prostate A, 62 samples for prostate B, 44 samples for prostate C, 55 samples for prostate D, and 61 samples for prostate E. All pieces were stored separately in RNAlater RNA Stabilization Reagent (Qiagen, Hilden, Germany) at $-20{ }^{\circ} \mathrm{C}$.

Tissue immediately adjacent to the tissue cross-section used in mRNA measurements was fixed in formalin and embedded in macro paraffin blocks (FFPE) to enable examination of tissue morphology. Sections were cut directly from the superior and inferior side of the crosssection used in mRNA measurements, stained with hematoxylin and eosin (HE), and inspected for cancer foci and prostatic epithelial neoplasia (PIN) lesions by an experienced uro-pathologist. The locations of carcinoma areas and PIN lesions were marked and the slides were scanned into digital images. All five prostate crosssections contained cancerous areas and cross-sections B and $\mathrm{C}$ contained also PIN lesions.

The study protocol was approved by the Ethics Committee of the Hospital District of Southwest Finland and it was in accordance with the Helsinki Declaration of 1975 , as revised in 1996, with written informed consent obtained from each participant.
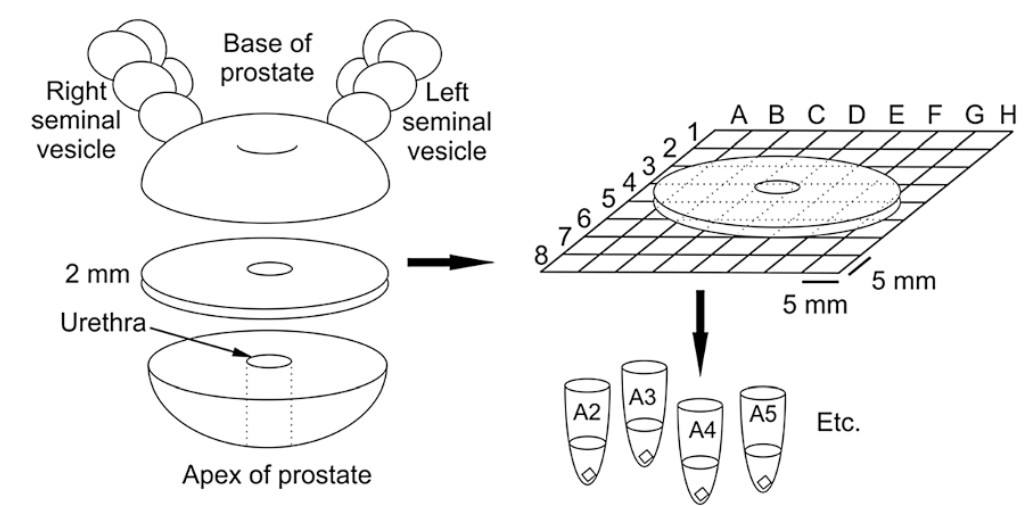

Fig. 1 Flowchart of the sample collection protocol for mRNA experiments. A horizontal cross-section slice of $2 \mathrm{~mm}$ in thickness was cut from the middle of each prostate and laid flat on a cutting plate while recording the original orientation of the slice in the organ. The slice was further cut into $5 \times 5 \mathrm{~mm}$ pieces according to a grid and each sample was stored separately in an RNA stabilizer solution 


\section{Real-time PCR for PCA3 and TMPRSS2-ERG mRNAs}

RNA extraction and reverse transcription were performed with RNeasy Mini kit (Qiagen, Germany) and High Capacity cDNA Archive kit (Applied Biosystems, USA) according to manufacturer's instructions and as described previously [10]. Artificial internal standard RNA was added to each sample at the beginning of RNA extraction process, after cell lysis [11].

Quantitative real-time PCR assays using a closed-tube concept [12] and time-resolved fluorometry-based detection were performed as described previously $[9,10]$ to measure PCA3 and TMPRSS2-ERG mRNA levels in each tissue piece. Levels of $K L K 3$ (kallikrein-related peptidase 3 , gene encoding PSA) mRNA and internal standard RNA were also measured for control and normalization purposes [11-14]. The oligonucleotide sequences are presented in Table 1. External DNA standards (Table 2) were used to form a standard curve and the lowest dilutions equal the limits of detection for the particular assays.

\section{Immunohistochemistry}

For immunohistochemistry (IHC) experiments, sections of 3-4 $\mu \mathrm{m}$ were cut from the FFPE tissue macro blocks immediately from the superior and inferior side of the HE-stained sections. The sections were pretreated in xylene and ethanol, and the heat-induced antigen retrieval was performed in a microwave oven using Target Retrieval Solution (Dako) followed by cooling at RT. Staining was performed by incubating the slides for one hour at RT in a humid chamber with rabbit monoclonal ERG antibody (clone EPR3864; Epitomics) that was used in 1:250 dilution. EnVision ${ }^{\text {Th }}+$ Dual Link System-HRP (Dako) was used as the secondary antibody with a 30-min incubation at RT. The staining was visualized by incubation in $\mathrm{DAB}+$ Chromogen solution (Dako) for $10 \mathrm{~min}$ at RT. After counterstaining with hematoxylin, dehydration, and treatment by xylene, the slides were analysed by an experienced uropathologist. The vascular endothelial cells served as

Table 1 Sequences of the primers and probes used in this study

\begin{tabular}{|c|c|c|c|}
\hline Oligonucleotide & Sequence $\left(5^{\prime}->3^{\prime}\right)$ & GenBank database sequence number & Position in sequence \\
\hline \multicolumn{4}{|l|}{ KLK3 } \\
\hline $5^{\prime}$ primer & TGA ACC AGA GGA GTT CTT GAC & X05332 & $523-543$ \\
\hline 3' primer & CCC AGA ATC ACC CGA GCA G & X05332 & $667-685$ \\
\hline reporter probe & СCT TCT GAG GGT GAA CTT GCG C & X05332 & $596-617$ \\
\hline quencher probe & AAT CAC CCT CAG AAG G & X05332 & $600-601,604-617$ \\
\hline \multicolumn{4}{|l|}{ mmPSA } \\
\hline $5^{\prime}$ primer & TGA ACC AGA GGA GTT CTT GCA & X05332 & $523-543$ \\
\hline $3^{\prime}$ primer & CCC AGA ATC ACC CGA GCG A & X05332 & $667-685$ \\
\hline reporter probe & CCT TCT GAG GGT GAT TGC GCA C & X05332 & $594-601,604-617$ \\
\hline quencher probe & AAT CAC CCT CAG AAG G & X05332 & $600-601,604-617$ \\
\hline \multicolumn{4}{|l|}{ PCA3 } \\
\hline $5^{\prime}$ primer & GGT GGG AAG GAC CTG ATG ATA C & AF103907 & $95-116$ \\
\hline 3' primer & GGG CGA GGC TCA TCG AT & AF103907 & $505-521$ \\
\hline reporter probe & AGA AAT GCC CGG CCG CCA TC & AF103907 & 478-497 \\
\hline quencher probe & CCG GGC ATT TCT & AF103907 & $478-489$ \\
\hline \multicolumn{4}{|l|}{ TMPRSS2-ERG III } \\
\hline $5^{\prime}$ primer & TAG GCG CGA GCT AAG CAG GAG & NM_005656.3 & $4-24$ \\
\hline 3' primer & GTA GGC ACA CTC AAA CAA CGA CTG G & NM_004449.4 & $338-362$ \\
\hline reporter probe & AGC GCG GCA GGA AGC CTT ATC AGT T & NM_005656.3 and NM_004449.4 & $57-64$ and $310-326$ \\
\hline quencher probe & TTC CTG CCG CGC T & NM_005656.3 and NM_004449.4 & $57-64$ and $310-314$ \\
\hline \multicolumn{4}{|l|}{ TMPRSS2-ERG VI } \\
\hline $5^{\prime}$ primer & CGG CAG GTC ATA TTG AAC ATT CC & NM_005656.3 & $73-95$ \\
\hline 3' primer & GCA CAC TCA AAC AAC GAC TGG & NM_004449.4 & $338-358$ \\
\hline reporter probe & CTT TGA ACT CAG AAG CCT TAT CAG TTG TGA & NM_005656.3 and NM_004449.4 & $139-149$ and $312-330$ \\
\hline quencher probe & GGC TTC TGA GTT CAA AG & NM_005656.3 and NM_004449.4 & $139-149$ and $312-317$ \\
\hline
\end{tabular}


Table 2 Dilutions of external DNA standards used in the real-time PCR assays

\begin{tabular}{llll}
\hline & \multicolumn{2}{l}{ Range (molecules per $\mathrm{mL}$ of template) } & Total number of points on standard curve \\
\cline { 2 - 3 } Target RNA & Lowest concentration & Highest concentration & 8 \\
\hline KLK3 & $2.5 \times 10^{3}$ & $2 \times 10^{11}$ & 7 \\
PCA3 & $1.3 \times 10^{3}$ & $2.5 \times 10^{11}$ & 4 \\
TMPRSS2-ERG III & $5 \times 10^{3}$ & $5 \times 10^{7}$ & 4 \\
TMPRSS2-ERG VI & $2 \times 10^{4}$ & $2 \times 10^{8}$ & 4 \\
\hline
\end{tabular}

positive controls for the staining with ERG antibody and cells of the benign glands as the negative control.

\section{Data analysis}

The specific locations of tissue were translated to match samples used for mRNA measurements by dividing the digital images of HE-stained tissue slides into equal amount of regions. Thus, potential shrinkage of the tissue was accounted for on average. Each sample piece was given coordinates on two axis (one giving values from A to $K$, and the other giving values from 1 to 10 ). Samples were classified into four categories based on morphology-based examination of the immediately adjacent HE-stained tissue. Sample was deemed as a carcinoma sample if one or both studied HE sections revealed adenocarcinoma at the same location, and PIN if one or both studied HE sections revealed PIN lesion. If both studied $\mathrm{HE}$ sections contained only histologically benign tissue in that area but the sample immediately next to the sample was classified as carcinoma or PIN sample, the sample was classified as "histologically benign tissue immediately adjacent to a carcinoma/PIN sample" (HBAC). If HE sections showed only histologically benign tissue in the sample and the samples next to it, sample was marked as histologically benign area (HB).

Samples were considered to contain measurable amounts of target mRNAs only when three PCR replicates gave a rise in fluorescence signals. Copy numbers were calculated as previously described [10], taking into account the potential RNA loss in extraction by using an internal RNA standard. For TMPRSS2-ERG mRNAs, samples that produced signal in only one or two out of the three PCR replicates were considered as samples where TMPRSS2-ERG mRNA expression was detectable but not quantifiable. Limits of detection for the realtime PCR assays are presented

Mann-Whitney $U$ test was used to study associations between mRNA and protein expression of the target genes and the histology of the tissue (SPSS 20.0, IBM).

\section{Results}

\section{Patient and tumour characteristics}

The essential clinicopathological characteristics of the five cases are presented in Table 3. All cases were clinically and pathologically organ confined. Two patients (B and D) had 5-alpha-reductase inhibitor therapy and one patient (E) had a combination therapy of 5-alpha-reductase inhibitor and $\alpha_{1}$ receptor antagonist prior to surgery. No positive margins were detected and all patients achieved serum PSA of $<0.1 \mathrm{ng} / \mathrm{mL}$ postoperatively. Using ultrasensitive PSA measurement, two patients had detectable postoperative serum PSA $(0.004$ and $0.026 \mathrm{ng} / \mathrm{mL})$. During the follow-up of 8-11 months, none of the patients had experienced clinical or biochemical recurrences. Patients D and $\mathrm{E}$ had clearly one index tumour, patients $\mathrm{A}$ and $\mathrm{C}$ had two or more carcinoma foci (between 6 and $18 \mathrm{~mm}$ ), and patient B had two small, well-differentiated carcinoma foci (both $<10 \mathrm{~mm}$ ).

\section{KLK3 mRNA expression}

$K L K 3$ mRNA levels were measured from all samples for control purposes. There were no statistically significant differences in KLK3 mRNA levels between carcinoma, PIN, HBAC, or HB samples (data not shown).

\section{PCA3 mRNA expression}

All five prostates showed $P C A 3$ mRNA expression. It was universally expressed in prostates $A$ and $B$ and in 80-96\% of samples of prostates C, D, and E. When all samples from the five prostates were combined, the median expression level was highest $\left(9.54 \times 10^{5}\right.$ mRNA copies/ $\mu$ g total RNA) in the samples that were classified as carcinoma samples, second highest in PIN samples, third highest in samples adjacent to carcinoma or PIN samples, and lowest in HB samples $\left(2.62 \times 10^{5}\right.$ mRNA

Table 3 Characteristics of the five patients included in the study

\begin{tabular}{llllll}
\hline Patient & Age & \multicolumn{2}{l}{ PSA $(\mathrm{ng} / \mathrm{mL})$} & Gleason sum & $\begin{array}{l}\text { Tumour } \\
\text { volume (\%) }\end{array}$ \\
\cline { 3 - 4 } & & preoperative & postoperative & \\
\hline A & 67 & 4.5 & $<0.003$ & $3+4$ & 10 \\
B & 59 & 9.2 & $<0.003$ & $3+3$ & 2 \\
C & 59 & 8.5 & $<0.003$ & $3+4$ & 5 \\
D & 67 & 16 & 0.026 & $4+3$ & 8 \\
E & 66 & 18 & 0.004 & $4+3$ & 15 \\
\hline
\end{tabular}

Tumour volume in the whole prostate was estimated based on the macro sections taken every $5 \mathrm{~mm}$ and covering the whole organ 


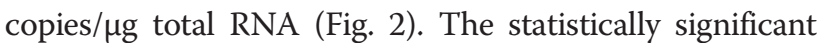
difference in median PCA3 mRNA values between carcinoma samples and HB samples was 3.6-fold $(p<0.001)$. The difference between carcinoma samples and samples adjacent to carcinoma or PIN was 3.1-fold $(p<0.001)$.

When the five studied prostate cross-sections were looked at individually, the same trend of statistically significantly higher PCA3 mRNA expression in carcinoma areas persisted only for prostate $C$, where the difference between medians of carcinoma and HB samples was 20 -fold $(p<0.003)$, and for prostate $\mathrm{D}$ with a 5.2 -fold difference $(p<0.001)$.

\section{TMPRSS2-ERG mRNA expression}

TMPRSS2-ERG III mRNA was detected in 3 out of 5 prostates (B, C, and E) and TMPRSS2-ERG VI mRNA in 2 out of 5 prostates (prostates $C$ and $E$ ). The samples containing detectable TMPRSS2-ERG expression and their location in relation to carcinoma areas are depicted in Fig. 3. Reliably quantifiable expression of TMPRSS2ERG III or VI mRNAs was found in four histologically benign samples, two of which were HBAC samples. The third sample was located next to a PIN lesion and the fourth resided in an area that was regarded as histologically benign. In addition, detectable but not quantifiable expression of these mRNAs was found in one carcinoma focus of prostate $\mathrm{C}$, one carcinoma sample of prostate $\mathrm{E}$, in four HBAC samples, and in five HB samples. One of the HB samples was adjacent to a PIN area. None of the

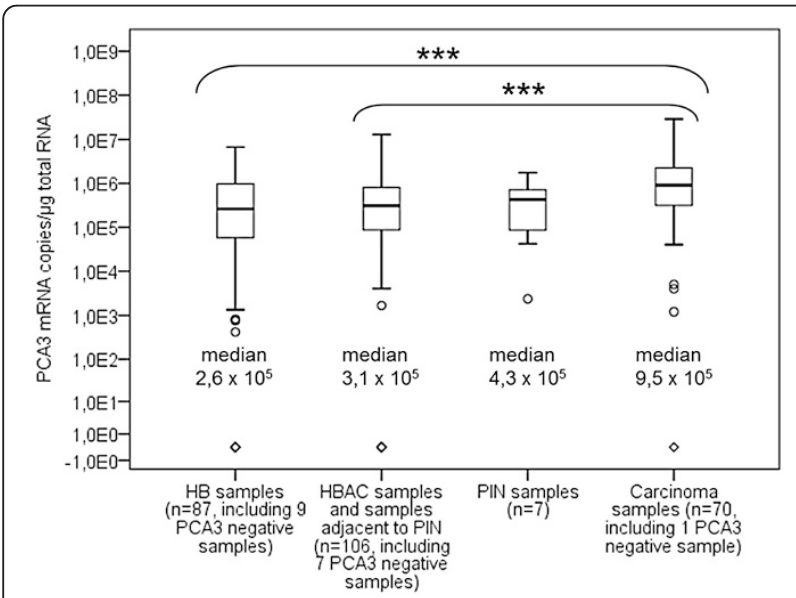

Fig. 2 PCA3 mRNA levels in tissue samples from the five studied prostates. The boxes contain interquartile ranges with median values shown as horizontal lines and the whiskers extending to minimum and maximum values. The statistical outliers are depicted with circles and negative samples with open diamonds. Statistically significant differences between the sample groups are marked with stars, and three stars denote a $p$ value of less than 0.001 . HB, histologically benign samples; HBAC, histologically benign samples adjacent to carcinoma; PIN, prostatic intraepithelial neoplasia individual samples showed simultaneous expression of both TMPRSS2-ERG mRNA isoforms.

\section{ERG protein expression}

IHC experiments detected positive ERG staining only in prostate $\mathrm{C}$ (Fig. 4). Based on the morphological analysis, all ERG positive areas contained carcinoma tissue. TMPRSS2-ERG mRNA was detectable in one out of the four individual tissue samples matching the ERG positive areas and the other three samples were located adjacent to TMPRSS2-ERG mRNA positive samples. One of the samples contained TMPRSS2-ERG III mRNA and the others TMPRSS2-ERG VI mRNA, but the amounts were not quantifiable in any of them. Areas in the same and other prostates containing either quantifiable or only detectable expression of TMPRSS2-ERG mRNAs were negative for ERG in IHC.

\section{Discussion}

Field effect is a recognized phenomenon in several cancers, including prostate cancer. It suggests that larger areas of the tissue than just the histologically identifiable tumour regions are changed on the molecular level. We studied the extent and location of the mRNA expression of two suggested prostate cancer markers, TMPRSS2-ERG fusion gene and $P C A 3$, in a systematic way in crosssections of cancerous prostates containing both histologically benign and carcinoma areas.

In addition to overexpression in tumours, increased expression of $P C A 3$ has been described also in areas adjacent to carcinoma foci and the phenomenon was explained by a carcinogenic field effect [3]. The thus far reported findings of TMPRSS2-ERG in $\mathrm{BPH}$ (benign prostatic hyperplasia) tissue, or in a benign area from a cancerous prostate, have sometimes been speculated to result from small carcinoma foci that resided in sampled tissues and were unnoticed despite microscopic examination $[5,7]$. Also the possibility of the samples containing precancerous tissue has been proposed [6, 7]. Our previous study, showing that $44 \%$ of the histologically benign sampled areas of cancerous prostates contained TMPRSS2-ERG mRNA transcripts in contrast to none of the seven benign tissues of cancer-free prostates [9], led us to hypothesize on TMPRSS2-ERG expression not being limited to carcinoma foci in cancerous prostates.

The fusion gene mRNAs were detectable in two carcinoma samples in this study, and also in 13 histologically benign samples. However, eight of the TMPRSS2-ERG positive histologically benign samples resided immediately next to samples classified as carcinoma or PIN. Due to the sample collection set-up, those samples could also contain cancer cells originating from the adjacent sample areas as the protocol of matching tissue morphology with the location of samples used for mRNA measurements was not 
TMPRSS2-ERG mRNA expression

Prostate A

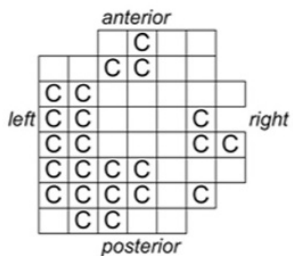

Prostate B

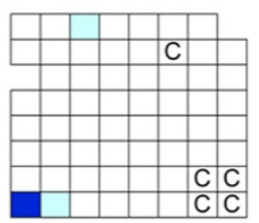

Prostate C

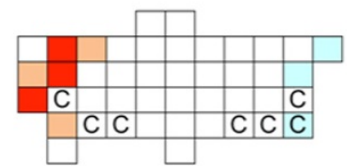

Prostate D

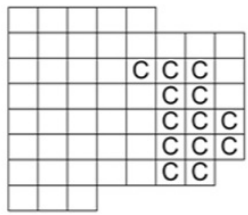

Prostate $\mathrm{E}$

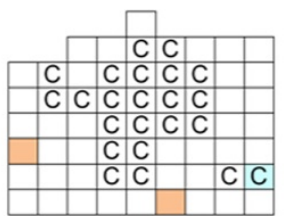

ERG protein expression
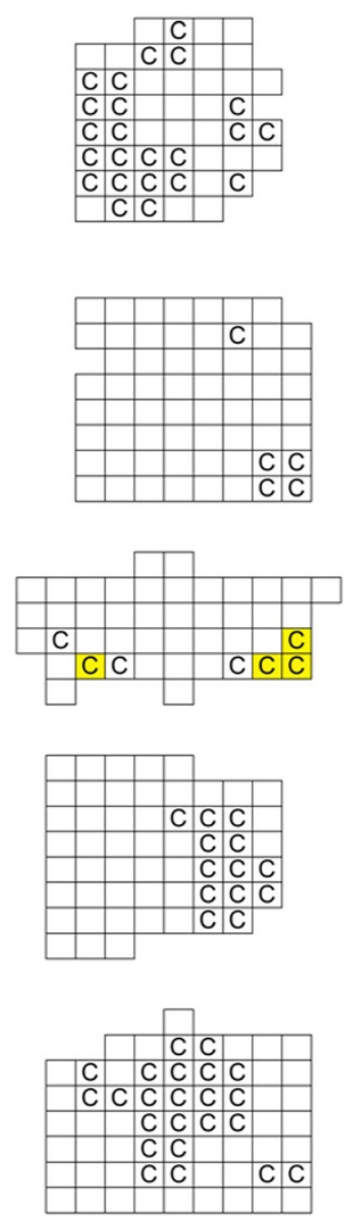

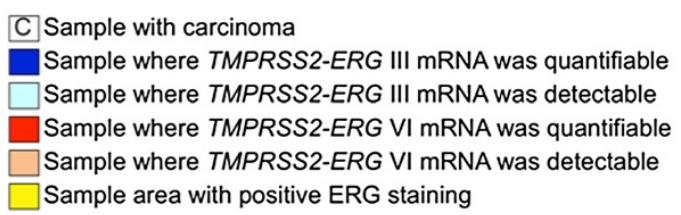

Fig. 3 Location of detected TMPRSS2-ERG mRNA expression and ERG protein expression in relation to carcinoma areas. Morphologically determined carcinoma areas are marked with $C$ in the five prostates. Dark blue boxes denote samples with quantifiable TMPRSS2-ERG III mRNA expression, and light blue boxes represent samples with detectable but not quantifiable TMPRSS2-ERG III mRNA expression. Red boxes denote samples with quantifiable TMPRSS2-ERG VI mRNA expression and light orange boxes represent detectable but not quantifiable TMPRSS2-ERG VI mRNA expression. Yellow boxes denote ERG protein expression. TMPRSS2-ERG mRNAs were found in prostates B, C, and E and ERG protein expression only in prostate C. None of the samples showed simultaneous expression of both TMPRSS2-ERG mRNA variants

able to fully account for site-specific tissue shrinkage caused by the fixation of the tissue. Yet we detected TMPRSS2-ERG expression in five samples without evidence of carcinoma foci in the immediate vicinity. In contrary to our previous study [9], none of the individual samples in this limited cohort showed simultaneous expression of both studied TMPRSS2-ERG isoforms. The detection rate in cancerous samples was also higher, $66 \%$, in the previous study, which could potentially be due to the sampling protocol which was more laborious and timeconsuming in this study, potentially leading to RNA degradation and thus lower detection rates.

The tissue regions that were positively stained in ERG IHC matched the locations of carcinoma lesions, and either contained detectable TMPRSS2-ERG mRNA or were located adjacent to samples that did. However, all 


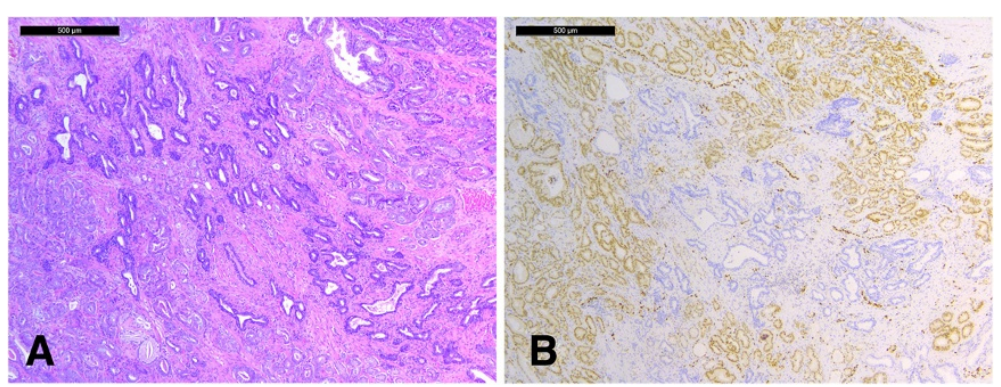

Fig. 4 Histology of prostate C showing (a) HE staining and (b) immunohistochemical ERG staining from the same area. The nuclei of malignant glands stain positively for ERG suggesting that ERG is overexpressed due to TMPRSS2-ERG fusion. Scale bar $500 \mu \mathrm{m}$

TMPRSS2-ERG mRNA positive areas did not stain positively for ERG even within a specific prostate, suggesting that the mRNA assays can reveal additional suspicious areas compared to IHC methods alone. This could be due to the IHC-negative areas not producing such amounts or forms of ERG protein that the antibody recognizes, even though previous reports of it have demonstrated correct identification of all the samples with the TMPRSS2-ERG rearrangement [15]. The rearrangement variant type did not seem to play a role in identifying ERG protein expression.

$P C A 3$ is a non-coding gene that does not produce a functional protein, so its expression was studied only on the mRNA level. PCA3 is reported to be 10-100-fold overexpressed in prostate tumours [16, 17], but in our previous studies, we have seen values of this magnitude only when carcinomas were compared to prostates without clinical prostate cancer [9] and a 5.8-fold increase of $P C A 3$ expression in tumours was observed when they were compared to benign areas of cancerous prostates [8]. In this cross-section study, we detected a three times higher expression in the carcinoma samples than in the histologically benign areas next to malignant tumours or at locations further away. It would therefore seem that the increase in PCA3 mRNA expression is not limited to the carcinoma foci in a cancerous prostate, but rather that there is a more global field change.

The set-up of this study is admittedly of a preliminary and experimental nature and due to the small size of the cohort, the conclusions can only be suggestive. The fact that only approximately half of prostate cancer cases are TMPRSS2-ERG positive [18] contributed to the even smaller number of TMPRSS2-ERG positive cases in our study. Additionally, we only studied one section of each prostate here in order to ensure the reliability of the routine pathological diagnostic procedure. This, however, could limit the conclusions drawn considering that prostate cancer, as also was seen in these specimens, is often a multifocal disease. The neoadjuvant therapy administered to three of the patients could also have had an effect on the results. However, despite these limitations, we find the set-up of this study novel and of interest. Clark and colleagues conducted a similar type of study using prostate cross-section slices and obtaining samples from cancerous and nonmalignant areas of the prostate, deemed as such based on the morphology of the slices above and below [5]. They, however, only looked at two matched samples from each prostatectomy specimen instead of the more systematic approach adopted here, which comprised a systematic and quantitative examination of mRNA levels throughout the tissue slice.

Utilizing these findings for diagnostic purposes would entail qRT-PCR assays performed on biopsies or tissue material obtained from transurethral resection of the prostate (TURP), where a finding of TMPRSS2-ERG mRNAs or high $P C A 3$ expression would indicate an increased risk of having or developing prostate cancer. While the routine formalin fixation may hamper the use of qRT-PCR assays, the recently introduced, alternative non-crosslinking fixatives such as PAXgene (Preanalytix) could be used for such purposes [19]. To our knowledge, there have been no reports of the fusion gene detected in tissues of men without any prostatic disorders, which supports the potential to use the fusion gene for risk analyses. However, there have been findings of TMPRSS2-ERG in the tissue of 6-8\% men with BPH but without history or suspicion of prostate cancer $[5,7]$. This is suggested to be due to the fusion gene being a sign of early changes in the gland, but not always leading to malignancy, and naturally means that a positive TMPRSS2-ERG mRNA test result does not require the presence of a current prostate carcinoma.

\section{Conclusions}

Our systematic study, despite its highly preliminary nature, shows that even though it is rare, it is possible to detect TMPRSS2-ERG transcripts in cancerous prostates in areas other than the carcinoma regions. If validated with larger cohorts and biopsy or TURP material, this could bring a new additive to assessment of risk of prostate cancer especially in men with negative biopsies. 


\section{Abbreviations}

BPH: Benign prostatic hyperplasia; CDNA: Complementary DNA; ERG: ETV-related gene; FFPE: Formalin-fixed, paraffin-embedded; HB: Histologically benign; HBAC: Histologically benign tissue immediately adjacent to a carcinoma/PIN sample; HE: Hematoxylin-eosin; IHC: Immunohistochemistry; KLK3: Kallikrein-related peptidase 3; mRNA: Messenger RNA; PCA3: Prostate cancer antigen 3; PCR: Polymerase chain reaction; PIN: Prostatic intraepithelial neoplasia; PSA: Prostate specific antigen; qRT-PCR: quantitative reversetranscription PCR; TMPRSS2: Transmembrane protease serine 2; TURP: Transurethral resection of the prostate.

\section{Competing interests}

The authors declare that they have no competing interests.

\section{Authors' contributions}

RMV participated in the study design and coordination, sample collection, and immunohistochemistry experiments; performed qRT-PCR assays and their data analysis; performed statistical analysis of the data; and drafted the manuscript. NTO participated in the sample collection; performed immunohistochemistry experiments, GRT-PCR assays, and their data analyses; and critically revised the manuscript for important intellectual content. PJB provided the clinical data; participated in the data interpretation; and critically revised the manuscript for important intellectual content. PT participated in the study design and coordination; performed the sample collection, histological examination of the tissue sections, and digital imaging; participated in the data interpretation; and critically revised the manuscript for important intellectual content. KP conceived the study; participated in the study design and coordination; participated in the data analysis and interpretation; and critically revised the manuscript for important intellectual content. All authors read and approved the final manuscript.

\section{Authors information}

Riina-Minna Väänänen is the corresponding author. Pekka Taimen and Kim Pettersson have a joint senior authorship.

\section{Acknowledgments}

The authors would like to thank Krista Bergendahl and Sinikka Collanus for excellent technical assistance.

\section{Author details}

${ }^{1}$ Department of Biotechnology, University of Turku, Turku, Finland ${ }^{2}$ Department of Urology, Turku University Hospital, Turku, Finland.

${ }^{3}$ Department of Pathology, University of Turku and Turku University Hospital, Turku, Finland.

Received: 20 April 2015 Accepted: 31 July 2015

Published online: 21 August 2015

\section{References}

1. Slaughter DP, Southwick HW, Smejkal W. Field cancerization in oral stratified squamous epithelium; clinical implications of multicentric origin. Cancer. 1953:6:963-8.

2. Ogden GR1, Cowpe JG, Green MW. Evidence of field change in oral cancer. Br J Oral Maxillofac Surg. 1990;28:390-2.

3. Popa I, Fradet $Y$, Beaudry G, Hovington H, Beaudry G, Têtu B. Identification of PCA3 (DD3) in prostatic carcinoma by in situ hybridization. Mod Pathol. 2007;20:1121-7.

4. Nonn L, Ananthanarayanan V, Gann PH. Evidence for field cancerization of the prostate. Prostate. 2009;69:1470-9.

5. Clark J, Merson S, Jhavar S, Flohr P, Edwards S, Foster CS, et al. Diversity of TMPRSS2-ERG fusion transcripts in the human prostate. Oncogene. 2007;26:2667-73.

6. Furusato B, Gao CL, Ravindranath L, Chen Y, Cullen J, McLeod DG, et al. Mapping of TMPRSS2-ERG fusions in the context of multi-focal prostate cancer. Mod Pathol. 2008:21:67-75.

7. Robert G, Jannink S, Smit F, Aalders T, Hessels D, Cremers R, et al. Rational basis for the combination of PCA3 and TMPRSS2: ERG gene fusion for prostate cancer diagnosis. Prostate. 2013;73:113-20.

8. Väänänen RM, Lilja H, Cronin A, Kauko L, Rissanen M, Kauko O, et al. Association of transcript levels of 10 established or candidate-biomarker gene targets with cancerous versus non-cancerous prostate tissue from radical prostatectomy specimens. Clin Biochem. 2013;46:670-4.

9. Väänänen RM, Lilja $H$, Kauko L, Helo P, Kekki H, Cronin AM, et al. Cancer-associated Changes in the Expression of TMPRSS2-ERG, PCA3, and SPINK1 in Histologically Benign Tissue From Cancerous vs Noncancerous Prostatectomy Specimens. Urology. 2014;83:511. e1-7.

10. Väänänen RM, Rissanen $M$, Kauko $O$, Junnila $S$, Väisänen $V$, Nurmi J, et al. Quantitative real-time RT-PCR assay for PCA3. Clin Biochem. 2008;41:103-8.

11. Nurmi J, Lilja H, Ylikoski A. Time-resolved fluorometry in end-point and real-time PCR quantification of nucleic acids. Luminescence. 2000;15:381-8.

12. Nurmi J, Wikman T, Karp M, Lövgren T. High-performance real-time quantitative RT-PCR using lanthanide probes and a dual-temperature hybridization assay. Anal Chem. 2002;74:3525-32

13. Nurmi J, Ylikoski A, Soukka T, Karp M, Lövgren T. A new label technology for the detection of specific polymerase chain reaction products in a closed tube. Nucleic Acids Res. 2000;28, E28.

14. Rissanen M, Helo P, Väänänen RM, Wahlroos V, Lilja H, Nurmi M, et al. Novel homogenous time-resolved fluorometric RT-PCR assays for quantification of PSA and hK2 mRNAs in blood. Clin Biochem. 2007:40:111-8.

15. van Leenders GJ, Boormans JL, Vissers $C J$, Hoogland AM, Bressers AA, Furusato B, et al. Antibody EPR3864 is specific for ERG genomic fusions in prostate cancer: implications for pathological practice. Mod Pathol. 2011:24:1128-38.

16. Bussemakers MJ, van Bokhoven A, Verhaegh GW, Smit FP, Karthaus HF, Schalken JA, et al. DD3: a new prostate-specific gene, highly overexpressed in prostate cancer. Cancer Res. 1999;59:5975-9.

17. Hessels D, Klein Gunnewiek JM, van Oort I, Karthaus HF, van Leenders GJ, van Balken B, et al. DD3 (PCA3)-based molecular urine analysis for the diagnosis of prostate cancer. Eur Urol. 2003;44:8-15.

18. Tomlins SA, Bjartell A, Chinnaiyan AM, Jenster G, Nam RK, Rubin MA, et al. ETS gene fusions in prostate cancer: from discovery to daily clinical practice. Eur Urol. 2009;56:275-86.

19. Staff S, Kujala P, Karhu R, Rökman A, Ilvesaro J, Kares S, et al. Preservation of nucleic acids and tissue morphology in paraffin-embedded clinical samples: comparison of five molecular fixatives. J Clin Pathol. 2013;66:807-10.

20. de Kok JB, Verhaegh GW, Roelofs RW, Hessels D, Kiemeney LA, Aalders TW, et al. DD3 (PCA3), a very sensitive and specific marker to detect prostate tumors. Cancer Res. 2002:62:2695-8.

21. Tomlins SA, Rhodes DR, Perner S, Dhanasekaran SM, Mehra R, Sun XW, et al. Recurrent fusion of TMPRSS2 and ETS transcription factor genes in prostate cancer. Science. 2005:310:644-8.

22. Cerveira N, Ribeiro FR, Peixoto A, Costa V, Henrique R, Jerónimo C, et al. TMPRSS2-ERG gene fusion causing ERG overexpression precedes chromosome copy number changes in prostate carcinomas and paired HGPIN lesions. Neoplasia. 2006;8:826-32.

\section{Submit your next manuscript to BioMed Central and take full advantage of:}

- Convenient online submission

- Thorough peer review

- No space constraints or color figure charges

- Immediate publication on acceptance

- Inclusion in PubMed, CAS, Scopus and Google Scholar

- Research which is freely available for redistribution 